\title{
CORRIGENDUM
}

\section{Structural basis of enzymatic benzene ring reduction}

Tobias Weinert, Simona G Huwiler, Johannes W Kung, Sina Weidenweber, Petra Hellwig, Hans-Joachim Stärk, Till Biskup, Stefan Weber, Julien J H Cotelesage, Graham N George, Ulrich Ermler \& Matthias Boll

Nature Chemical Biology; doi:10.1038/nchembio.1849; corrected online 7 July 2015 and 21 July 2015

In the version of this article initially published, the PDB code for the structure of BamBC as isolated was listed as $4 \mathrm{Z} 4 \mathrm{O}$, which was incorrect. The correct code is $4 \mathrm{Z} 40$. The error has been corrected for the PDF and HTML versions of this article.

\section{ERRATUM}

\section{Pharmacological targeting of the Wdr5-MLL interaction in C/EBP $\alpha \mathrm{N}$-terminal leukemia}

Florian Grebien, Masoud Vedadi, Matthäus Getlik, Roberto Giambruno, Amit Grover, Roberto Avellino, Anna Skucha, Sarah Vittori, Ekaterina Kuznetsova, David Smil, Dalia Barsyte-Lovejoy, Fengling Li, Gennadiy Poda, Matthieu Schapira, Hong Wu, Aiping Dong, Guillermo Senisterra, Alexey Stukalov, Kilian V M Huber, Andreas Schönegger, Richard Marcellus, Martin Bilban, Christoph Bock, Peter J Brown, Johannes Zuber, Keiryn L Bennett, Rima Al-awar, Ruud Delwel, Claus Nerlov, Cheryl H Arrowsmith \& Giulio Superti-Furga

Nat. Chem. Biol. 11, 571-578 (2015); published online 13 July 2015; corrected online 20 August 2015

In the author list, affiliation and correspondence information for Cheryl Arrowsmith was missing. Her name should be accompanied by affiliation number 3 (signifying the Structural Genomics Consortium, University of Toronto, Toronto, Ontario, Canada) and by an asterisk indicating her status as a corresponding author. These errors have been corrected in the HTML and PDF versions of the article.

\section{CORRIGENDUM}

\section{Structural basis for selective binding of $\mathrm{m}^{6} \mathrm{~A}$ RNA by the YTHDC1 YTH domain}

Chao Xu, Xiao Wang, Ke Liu, lan A Roundtree, Wolfram Tempel, Yanjun Li, Zhike Lu, Chuan He \& Jinrong Min

Nat. Chem. Biol. 10, 927-929 (2014); published online 21 September 2014; corrected after print 19 August 2015

In the version of this Brief Communication initially published, the email address for corresponding author, Chao Xu, was incorrect. It should be listed as chaor.xu@utoronto.edu. This error has been corrected in the PDF and HTML versions of the article. 